\title{
Economic Efficiency of Outsourcing Business Models: A Comparative Assessment
}

\author{
Flora Kulembayeva $^{1} \cdot$ Aruzhan Seitkaziyeva $^{2} \cdot$ Rakymzhan Yelshibayev $^{1}$
}

Received: 5 July 2021/ Accepted: 22 September 2021/Published online: 20 October 2021

(C) Global Institute of Flexible Systems Management 2021

\begin{abstract}
This study aims to form a methodological approach to assess outsourcing business models and identify the most acceptable one for a modern enterprise. The research methodology is based on the author's approach, which includes cognitive map analysis and a simplicial complex. The study was tested on two Information Technology companies in Russia. Based on the determination of the profit elasticity on the manageable vertices of outsourcing business models, the most attractive in terms of efficiency criterion in the form of profit is the outsourcing business model of developing in-house non-IT services. The analysis of structural connectivity made it possible to rank the factors by the level of importance for the preservation of the business model. Modeling the effectiveness of implementing the formed outsourcing business models provided an opportunity to increase profits for the investigated IT companies by increasing the number of single-type projects. The conducted modeling of changes in relations with customers in the studied IT enterprises shows the inexpediency of changing customer relations in BM3. It is proved that certain factors can be replaced without losing the integrity of the business model. The scientific contribution of this study is the proposed methodological approach for assessing the effectiveness of an outsourcing business model. Based on the application of this methodology, the strategic objectives are linked to the business model in the process of achieving them (the
\end{abstract}

Flora Kulembayeva

kulembayevafl@rambler.ru

1 Educational Program "Economics", Narxoz University, Almaty, Kazakhstan

2 SED Social Sciences, Narxoz University, Almaty, Kazakhstan achievement of strategic objectives under the influence of the selected outsourcing business model is shown).

Keywords Business model · Cognitive map · Efficiency · Outsourcing · Profit · Project budget $\cdot$ Simplex

JEL Codes M10 - M12 - M15 - M50 - M55

\section{Introduction}

In today's environment, businesses compete with each other to attract investment and financial resources, skilled workers, markets, new customer groups. Modern enterprises, due to the economic development of competition, promote new management tools, one of which is outsourcing. It provides an opportunity for companies to strengthen their competitive advantage in the marketplace. Such positions of enterprises and their further development greatly depend on the cost-effectiveness of outsourcing solutions (Zhu et al., 2017). Achievement of competitive advantages involves the effective use of all resources of an enterprise, cost optimization of not only the main business activities but also non-core ones, which are no less important for the normal functioning of a company (Nagurney et al., 2017). Therefore, there is an objective need to form an effective outsourcing business model to improve an enterprise's performance, focusing on core business and reducing investment in non-core assets to strengthen the competitive position.

Outsourcing has emerged as a response to the demands of the global market; it is based on the important principle of an efficiently organized economic system-the principle of the division of labor. It was thanks to the development of the market that it became possible to concentrate all the 
resources on the essential activity of an enterprise and transfer auxiliary functions to a reliable and professional partner (Chen et al., 2019). Sourcing models refer to modern ways of doing business, the direct content of which is the involvement of third-party resources. Based on their use, many companies have an opportunity to reduce their costs, pay more attention to basic business operations, and acquire new ideas (Cai et al., 2020). With the development of technology and entrepreneurship, various types of such models have emerged: outsourcing, noosourcing, crowdsourcing, etc. In the process of development, a "sourcing model" concept used in many fields was created. Its importance lies in the fact that it is the main factor and model for the development of the company's activities in attracting outside resources to improve the company's operations and solve certain business problems (Ciasullo et al., 2018).

The sourcing business model and its main types in the current market conditions are among the main factors of a competitive advantage for many businesses, giving them the opportunity to attract different types of resources to improve the performance. In the present, it is not only financial resources but also an innovative idea, which in the long term will provide positive financial results, expand the customer segment, the company's market share, and create favorable conditions for development (Agburu et al., 2017). The motivation for this study is the objective need to implement an outsourcing business model as an effective means of interconnection between the customer, the outsourcing company and the consumer, as well as the regulator of the company's effectiveness in the process of its development. At the same time, today's outsourcing model can have many modifications and features of functioning, so it is interesting to know which one of them is the most effective and whether it is possible to form a template universal model. This study aims to fill this gap in the science by assessing outsourcing business models and comparing their effectiveness. Therefore, the purpose of this study is to form a methodological approach to assess the effectiveness of outsourcing business models and identify the most effective among them.

\section{Literature Review}

The purpose of the business model is not only to reduce costs and increase profits, but also to find new customers, future employees, new ideas and the like. Today one can distinguish the following components of the sourcing business model:

- Access to a large number of talents (Liu et al., 2017);
- The productivity of the attracted labor resources is greater than that of the main workers;

- Personnel stability (high motivation, low turnover rate) (Balcet \& Ietto-Gillies, 2020);

- Long-term cost savings;

- Formation of competitive advantages for business in the market (Mayer \& Phillips, 2017);

- Social influence on employees, their families, organizations, and the like (Happonen \& Siljander, 2020).

Any sourcing model involves the transfer of certain information to unauthorized entities, which can lead to its leakage on the market, and, as a consequence, the loss of certain ideas, developments, confidential information that affects competitiveness (Singh \& Gonsalves, 2019). Legal regulation is not simple in all models. In the outsourcing model, it is possible to enter into a contract with an outside organization and insure against the disclosure of information. In crowdsourcing and noosourcing, however, the risk of disclosure increases because the main carriers of ideas here are people, their organizations or groups. This is due to the fact that the relationship between the company and the public is not actually enshrined in anything to date (Trang, 2017). The only way an enterprise can protect an idea presented by the public as a corporate one is intellectual property rights (Chen et al., 2017).

In the modern literature on management, the outsourcing model has the following characteristics:

- First, it includes the separation of the company's functions and transferring them to other business entities for implementation (Mussapirov et al., 2019);

- Secondly, there is a shift of responsibility to external suppliers for the availability of the enterprise's goods and services (Drzewiecki, 2021);

- Thirdly, the strategic use of external means for the implementation of actions carried out traditionally by the enterprise's personnel, who use internal means of the enterprise. This characteristic of the outsourcing business model is the allocation of certain support functions (non-core) from the organizational structure and entrusting their implementation to specialized, external organizations. This is the transfer to a third party of permanent managerial responsibility for the performance of the service defined in the agreement (Bilan et al., 2017).

The latest approaches that define the prospects for the development of outsourcing business models are of interest. The outsourcing business model is ofter defined as the assignment to organize a specific process, specifying the assignment outcomes, but without providing instructions as to how individual tasks are to be performed, leaving the 
initiative in this area to the recipient of this assignment (Ciasullo et al., 2018).

The business model of the company combines such functions as: the selection of customers, determining the quality and variety of services, defining the tasks of the company and its affiliates, resource allocation, entering the market and creating the necessary conditions to attract customers and generate profits (Bocken et al., 2018). Today, one can identify four main features of the outsourcing business model:

- Engaging third-party companies to perform certain work and tasks (Rehman et al., 2018);

- Use of temporary staff without an employment contract (Wallo \& Kock, 2018);

- Reducing payroll costs (Bhushan et al., 2018);

- Reduction of non-core activities (Yuan et al., 2020).

The outsourcing model is the most developed and popular. The essence of its use lies in the transfer by the company of part of its business tasks or functions to thirdparty performers based on a pre-contract. The implementation of this model provides revenue growth for corporations and companies; it is also a platform for the development of other creative models (Richter et al., 2018). In addition, there are the following main types of outsourcing:

- Outstaffing-formed on the basis of the lease of temporary (seasonal) employees to perform various works (Blagorazumnaia, 2018);

- Insourcing is the creation of the company's own separate business unit, providing services both to internal departments and external users (Johansson et al., 2021);

- Cosourcing - the performance of certain activities at the expense of their own staff and external performers (Jokipii \& Di Meo, 2019);

- Offshoring (or offshore outsourcing) - the transfer of unimportant business processes to executing companies in another geographic location (Munjal et al., 2019);

- Multisourcing - the distribution of work among several outsourcers, each of which is universal (Könning et al., 2019).

It should also be noted that in management scientific literature, considerable attention is paid to the process of outsourcing as a process of transferring a number of nonkey functions to the provider of outsourced services (Pankowska, 2019). However, it is not taken into account that the activities of business entities, like the entrepreneurial structure itself, are a systemic entity.

When developing an outsourcing business model, it is necessary to take into account its focus on the implementation of competitive strategies. Each component of the outsourcing business model should be an element of the overall mechanism to improve the competitiveness of business entities (Austin-Egole \& Iherioanma, 2020). Nevertheless, an outsourcing business model should not be based only on resources (material, personnel, etc.) or be considered as a model of resource provision. This is a narrow approach. Besides, one should agree with the researchers who believe that entrepreneurs who have strategically chosen the outsourcing business model tend to take advantage of outsourcing as an integrated form of business administration. This form potentially mitigates the internal business conflict caused by the objective shortage of internal resources and the need not only to preserve but also to constantly acquire the company's competitive advantages (Modak et al., 2019). As the complexity of the outsourcing process changes, other parameters such as riskiness, flexibility, security of the customer enterprise change. Therefore, there is a need to form a business model of the intelligence-intensive (knowledge-oriented) nature of business processes for outsourcing (Moradi et al., 2019).

Despite the diversity of approaches to the formation of the outsourcing business model, they all indicate that business models of outsourcing in today's rapidly changing business environment should be flexible. There are studies that identify the rules and elements of a flexible framework for implementing effective outsourcing partnerships"vested outsourcing" (Vitasek \& Manrodt, 2012). The flexibility achievable with different business models is determined by exploring how companies can select and integrate the following three interacting components to develop flexible business models: network influences, transactional relationships, and corporate ownership (Mason \& Mouzas, 2012). However, different business models are characterized by different priorities in responding to changes in the value chain (Tan, 2021). The transformation of the business model from participation in a joint venture to supplier-customer interaction, which has a complementary or competitive nature, is also due to the strategic flexibility of the organization (Parameswar \& Dhir, 2020). Especially relevant is the introduction of such models in a crisis, as they contribute to the dynamic adaptation to the uncertainty of the business environment (Evans \& Bahrami, 2020). Thus, it is the flexibility of the model in the current environment that is the key driver for ensuring its survival (including in the face of the COVID-19 pandemic), as well as the economic efficiency of the business (Klafke et al., 2021; Masudin et al., 2021; Paul \& Chowdhury, 2020; Vergara et al., 2021).

In the outsourcing business model, each process and element occupies a specific place and performs a specific function. The transfer of a number of non-key functions changes the internal structure (organizational architecture) of the company. This should be reflected in the creation of 
a new business model (Richter et al., 2018). In this regard, the introduction of the outsourcing process into the system of business processes requires a change in the type of business model. There is an objective need to build an outsourcing business model that takes into account systemic changes associated with the interaction with an outside company and a chance in a number of internal enterprise processes. Therefore, this study aims to form a methodological approach to assessing the effectiveness of outsourcing business models (namely, to determine their structures and compare the effectiveness of their functioning elements).

\section{Materials and Methods}

This study proposes a methodical approach to diagnose the effectiveness of the outsourcing model; it provides a complete description and quantitative assessment of a model through nine groups of indicators. They show the logic of how the company intends to make a profit: customer segments (CS); value propositions (VP); customer relations (CR); marketing channels (MC); revenue streams (RS); key resources (KR); key activities (KA); key partners (KP); and cost structure (ST).

The proposed methodology was tested on the materials of two Russian IT companies. Insufficient development of the software market in Russia and legislation on the protection of intellectual property rights hinders the qualitative development of Russian IT companies. For these reasons, it is common practice to register IT enterprises with product business models abroad. As a consequence, the qualitative development of Russian IT companies is constrained. Therefore, this study is focused on the evaluation of outsourcing business models of the Russian IT market representatives. To conduct a comparative characterization of these models, the companies "Atlon" and "Deasoft" were chosen. The strategic level is based on the balanced scorecard by R. Kaplan and D. Norton (Modak et al., 2017) and is used to monitor the achievement of long-term goals by the IT enterprise. It consists of four groups of indicators related to specific blocks of the business model:

(1) Finance (F): cost structure, revenue streams;

(2) Customers (C): customer segments, customer relationships, sales channels;

(3) Proposition (P): value proposition;

(4) Value creation (V): key activities, key resources, and key partners.

Such grouping allows one to link the business model to strategic indicators, which makes it possible to quantify the business model.

This study proposes a cognitive map of the business model level, which is built for eight basic business models of IT companies: BM1-consulting; BM2-custom calculations; BM3-outstaffing; BM4-auxiliary outsourcing; BM5-custom software development with subsequent support; BM6 - software development for sale; BM7-own service development and support; BM8-own service development for non-IT services.

The evaluation of the relationship between the factors was performed using the linguistic variable (very low, below average, average, above average, high, very high) and the nature of the impact (increases, decreases, no impact). The scale values presented in Table 1 were used to construct the cognitive model.

The grouping of indicators by blocks of the business model template (Fig. 1) allows one to take into account the emergence of new business models or individual successful solutions. The cognitive map of the business model is based on the grouping of fifty-six factors of business models of IT enterprises according to the template blocks of Osterwalder (Osterwalder \& Euchner, 2019).

Thus, any business model can be described using a cognitive map with a fixed structure (Fig. 1).

Based on the analysis of the cognitive map of the outsourcing business model, the list of possible links between blocks of the business model is defined (Table 2).

Thus, the comprehensive economic and organizational model can be described using the appropriate cognitive map (Fig. 2), and the above approaches can be used to assess the effectiveness of changing or improving the outsourcing business model of the IT enterprise. The blocks of the development management level (DLM) are specified.

When using the economic-organizational model for different business models, each business model will be represented as a subset of the same list of factors for all business models:

$V^{k} \in V=\left\{v_{i}\right\}, i=1,2, \ldots, N$

where $V$-the set of all vertices of the cognitive map of the outsourcing business model; $N$-the total number of vertices in the complete cognitive map of business models.

Thus, the economic-organizational model when an IT enterprise uses different outsourcing business models will differ only in the cognitive map of the business model, which is an oriented graph $G^{k}$, defined by the set of vertices $V^{k}$ and the adjacency matrix $E^{k}$ :

$G^{k}=\left\langle V^{k}, E^{k}\right\rangle$,

where $V^{k}$ - the set of vertices of the cognitive map of the business model $k, k=1,2, \ldots K$; $K$-total number of business models under consideration; $E^{k}$ - the adjacency matrix of the business model's cognitive map vertices $k, E^{k}, \in E$.

$E$ reflects the connection between the two vertices: $E=\left\{e_{i j}\right\}$. The connection is expressed through $\{0,1\}$. 
Table 1 Scale of values to assess the relationship between the factors of the outsourcing business model. Source: Formed by the author

\begin{tabular}{lll}
\hline Textual interpretation & Value range & Mean \\
\hline Very low & $0.00-0.15$ & 0.08 \\
Low & $0.15-0.25$ & 0.20 \\
Below average & $0.25-0.45$ & 0.35 \\
Average & $0.45-0.65$ & 0.55 \\
Above average & $0.65-0.85$ & 0.75 \\
High & $0.85-0.95$ & 0.90 \\
Very high & $0.95-1.00$ & 0.98 \\
\hline
\end{tabular}

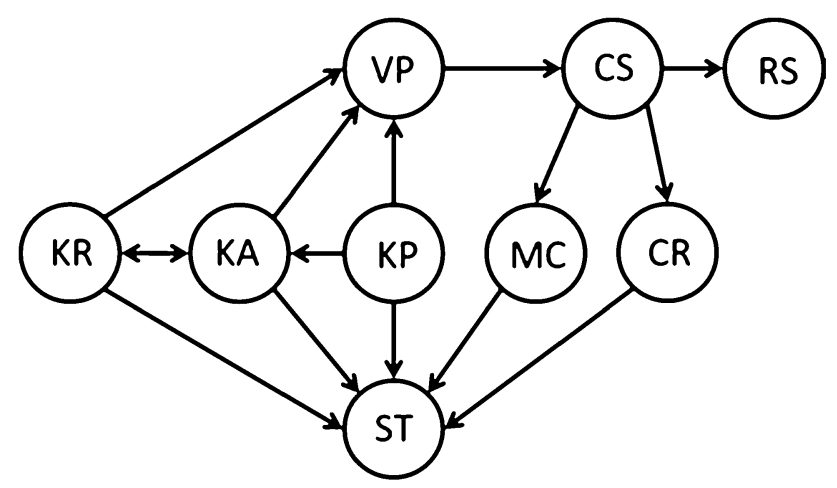

Fig. 1 Cognitive map of the business model. Source: Formed by the author weighting factor $w_{i j}$, or a function $f_{i j}$. In this case, the connection can be both positive and negative, and in the absence of reliable information about the connection, it can be described by fuzzy numbers. Thus, it is possible to consider $G^{k} \in G$, where $G=\langle V, E\rangle$-a complete cognitive map of the IT enterprise business models (Fig. 3).

Cognitive maps with the grouping of vertices by blocks of the business model template are shown for business models BM1-BM8 in Fig. 3.

As can be seen from Fig. 3, the dependencies KR $\rightarrow$ $\mathrm{KA}, \mathrm{KR} \rightarrow \mathrm{ST}, \mathrm{KA} \rightarrow \mathrm{ST}, \mathrm{KP} \rightarrow \mathrm{ST}, \mathrm{MC} \rightarrow \mathrm{ST}$, $\mathrm{CR} \rightarrow \mathrm{ST}, \mathrm{KA} \rightarrow \mathrm{VP}, \mathrm{VP} \rightarrow \mathrm{CS}, \mathrm{CS} \rightarrow \mathrm{RS}, \mathrm{CS} \rightarrow \mathrm{MC}$, and $\mathrm{CS} \rightarrow \mathrm{CR}$ are inherent in all models. Other dependencies are found only in the following business models:

- $\mathrm{KP} \rightarrow \mathrm{KA}$-in all except BM3;

- $\mathrm{KP} \rightarrow \mathrm{VP}$-in BM6, BM7, and BM8;

- $\mathrm{KR} \rightarrow \mathrm{VP}$-in BM6, BM7, and BM8;

- $\mathrm{KA} \rightarrow \mathrm{KR}$-in all except BM1 and BM8.

Thus, all factors in relation to business models can be divided into three groups:

(1) Specific to a particular business model: CS_04, CS_05, CS_06, CS_07, VP_01, VP_02, VP_O3, VP_04, VP_07, VP_09, V_10, V_11, V_12, VP_13, VP_14, RS_02, RS_03, RS_04, RS_05, RS_07, KR_05, KR_06, KP_01;

(2) Inherent in several business models: CS_01, CS_02, CS_03, CS_08, CS_09, VP_05, VP_06, VP_08, VP_15,

Table 2 Cognitive map vertices connections at the block level of the outsourcing business model template. Source: Formed by the author

\begin{tabular}{lll}
\hline Business model block & Effects blocks & Depends on the blocks \\
\hline CS & $\{\mathrm{CR}, \mathrm{MC}, \mathrm{RS}\}$ & $\{\mathrm{VP}\}$ \\
$\mathrm{MC}$ & $\{\mathrm{ST}\}$ & $\{\mathrm{CS}\}$ \\
$\mathrm{CR}$ & $\{\mathrm{ST}\}$ & $\{\mathrm{CS}\}$ \\
$\mathrm{VP}$ & $\{\mathrm{CS}\}$ & $\{\mathrm{KA}\}$ \\
& $\{\mathrm{RS}, \mathrm{CS}\}$ & $\{\mathrm{KR}\}$ \\
& & $\{\mathrm{KP}\}$ \\
$\mathrm{RS}$ & $\{\mathrm{KA}, \mathrm{KP}\}\{\mathrm{KA}, \mathrm{KR}\}\{\mathrm{KP}, \mathrm{KR}\}\{\mathrm{KA}, \mathrm{KP}, \mathrm{KR}\}$ \\
& & $\{\mathrm{CS}\}$ \\
$\mathrm{KR}$ & $\{\mathrm{KA}, \mathrm{ST}\}$ & $\{\mathrm{CS}, \mathrm{VP}\}$ \\
& $\{\mathrm{ST}, \mathrm{VP}\}\{\mathrm{KA}, \mathrm{ST}, \mathrm{VP}\}$ & $\{\mathrm{KA}\}$ \\
$\mathrm{KP}$ & $\{\mathrm{KA}, \mathrm{ST}\}$ & \{\} \\
& $\{\mathrm{ST}, \mathrm{VP}\}\{\mathrm{KA}, \mathrm{ST}, \mathrm{VP}\}$ & \\
$\mathrm{KA}$ & $\{\mathrm{ST}, \mathrm{VP}\}\{\mathrm{KR}, \mathrm{ST}\}$ & $\{\mathrm{KP}\}\{\mathrm{KR}\}\{\mathrm{KP}, \mathrm{KR}\}$ \\
$\mathrm{ST}$ & $\{\mathrm{KR}, \mathrm{ST}, \mathrm{VP}\}$ & \\
& \{\} & $\{\mathrm{CR}, \mathrm{MC}, \mathrm{KP}\}\{\mathrm{CR}, \mathrm{MC}, \mathrm{KR}\}$ \\
& & $\{\mathrm{CR}, \mathrm{MC}, \mathrm{KP}, \mathrm{KR}\}\{\mathrm{CR}, \mathrm{KA}, \mathrm{MC}, \mathrm{KP}\}\{\mathrm{CR}, \mathrm{KA}, \mathrm{MC}, \mathrm{KR}\}\{\mathrm{CR}, \mathrm{KA}, \mathrm{MC}, \mathrm{KP}, \mathrm{KR}\}$
\end{tabular}

$\{\mathrm{CR}, \mathrm{KC}, \mathrm{RS}\}$-simultaneous connection to blocks $\mathrm{CR}, \mathrm{KC}$, and RS; $\{\mathrm{KP}\}\{\mathrm{KR}\}$-connection to either the $\mathrm{KP}$ or $\mathrm{KR}$ block; \{\}$-$ lack of connection to one of the blocks 


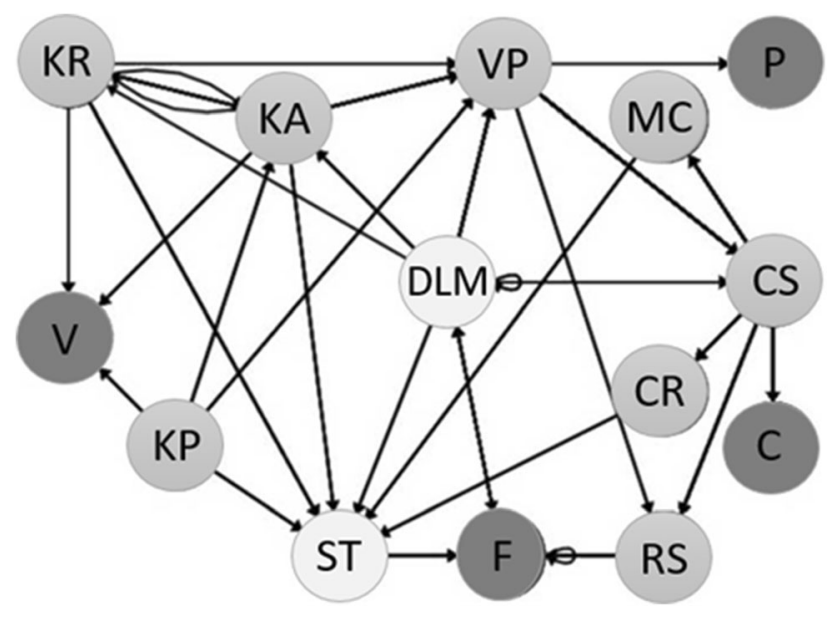

Fig. 2 Cognitive map of the three-level indicator system. Source: Formed by the author

VP16, VP17, VP18, MC_02, MC_03, CR_01, CR_02, CR_03, RS_01, RS_06, KR_01, KR_02, KR_03, KR_04, KR_07, KA_01, KA_02, KA_03, KP_02, KP_03, ST_03;

(3) Common to all business models: MC_01, ST_01, ST_02.

Thus, topological analysis of cognitive maps of business models is the analysis of similar systems and finding the conditions for transition of one outsourced business model to another or even the creation of new business models based on accumulated knowledge. Topological (or polyhedral) analysis assumes two finite sets $X$ and $Y$, elements of which are connected by binary relations $\lambda$. For the cognitive map, $X=Y=V$, and $\lambda$ can be calculated using the following formula:

$\lambda=\left\{\lambda_{i j}\right\}, \lambda_{i j}= \begin{cases}1, & \text { if } v_{i} \text { affects } v_{j}, \\ 0, & \text { if } v_{i} \text { has no effect on } v_{j}\end{cases}$

where

$v_{i} \in X, v_{j} \in Y, i=1,2, \ldots, N, j=1,2, \ldots M, N=M$-the number of vertices of the set $V$.

A simplicial complex is formed by a set of simplexes connected by common faces, i.e., by common vertices (Awa \& de la Cruz, 2020). In doing so, one considers both the impact of $X$ on $Y$ by using $\lambda$, and vice versa. In considering the connection $X$ with $Y$, the transposed relation matrix is used $\lambda^{T}$. In the first case, the simplicial complex $K_{X}(Y, \lambda)$ is formed by multiple simplexes $\sigma_{X}(Y, \lambda)$, in the second $K_{Y}\left(X, \lambda^{T}\right)$ - by using $\sigma_{Y}\left(Y, \lambda^{T}\right)$. Simplicial complex $K_{X}(Y, \lambda)$ can be represented by the incidence matrix $\lambda$, which shows that the vertice enters $y_{j}$ of simplex $\sigma^{x_{i}}$ :

$$
\begin{array}{lllllll} 
& y_{1} & y_{2} & \ldots & y_{j} & \ldots & y_{M} \\
\sigma^{x_{1}} & \lambda_{11} & \lambda_{12} & \ldots & \lambda_{1 j} & \ldots & \lambda_{1 M} \\
\sigma^{x_{2}} & \lambda_{21} & \lambda_{22} & \ldots & \lambda_{2 j} & \ldots & \lambda_{2 M} \\
\ldots & \ldots & \ldots & \ldots & \ldots & \ldots & \ldots \\
\sigma^{x_{i}} & \lambda_{i 1} & \lambda_{i 2} & \ldots & \lambda_{i j} & \ldots & \lambda_{i M} \\
\ldots & \ldots & \ldots & \ldots & \ldots & \ldots & \ldots \\
\sigma^{x_{N}} & \lambda_{N 1} & \lambda_{N 2} & \ldots & \lambda_{N j} & \ldots & \lambda_{N M}
\end{array}
$$

Simplex $\sigma_{q}^{x}$ consists of vertices $Y$, which depend on the vertices $X$. The number of vertices in the simplex is +1 , where q-the dimensionality of the simplex, or the number
Fig. 3 Cognitive maps of business models BM1-BM8. Source: Formed by the author
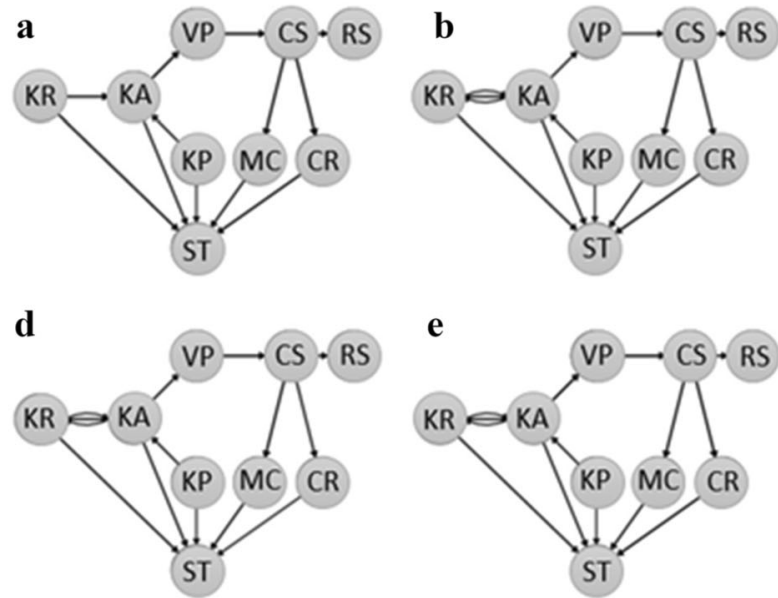

g

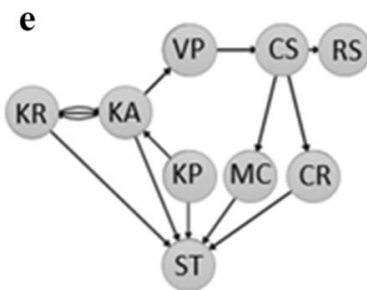

$\mathbf{h}$

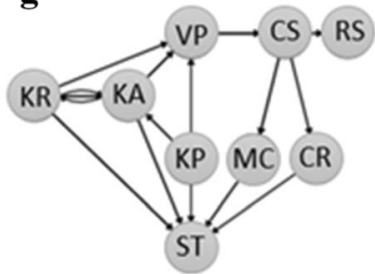

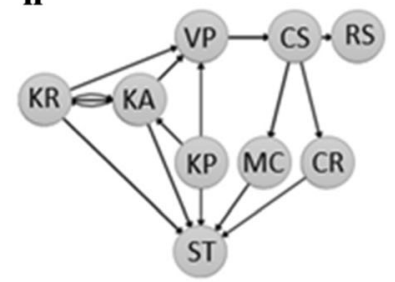
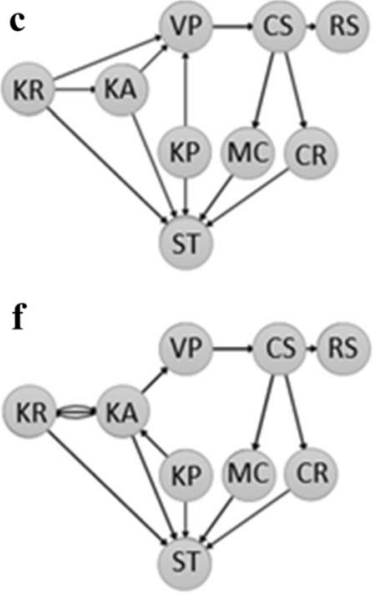

Note:

a) BM1

b) $\mathrm{BM} 2$

c) $\mathrm{BM} 3$

d) $\mathrm{BM} 4$

e) BM5

f) $B M 6$

g) $\mathrm{BM} 7$

h) $B M 8$ 
Fig. 4 Modeling the work of an IT enterprise using different outsourcing business models. Source: Formed by the author
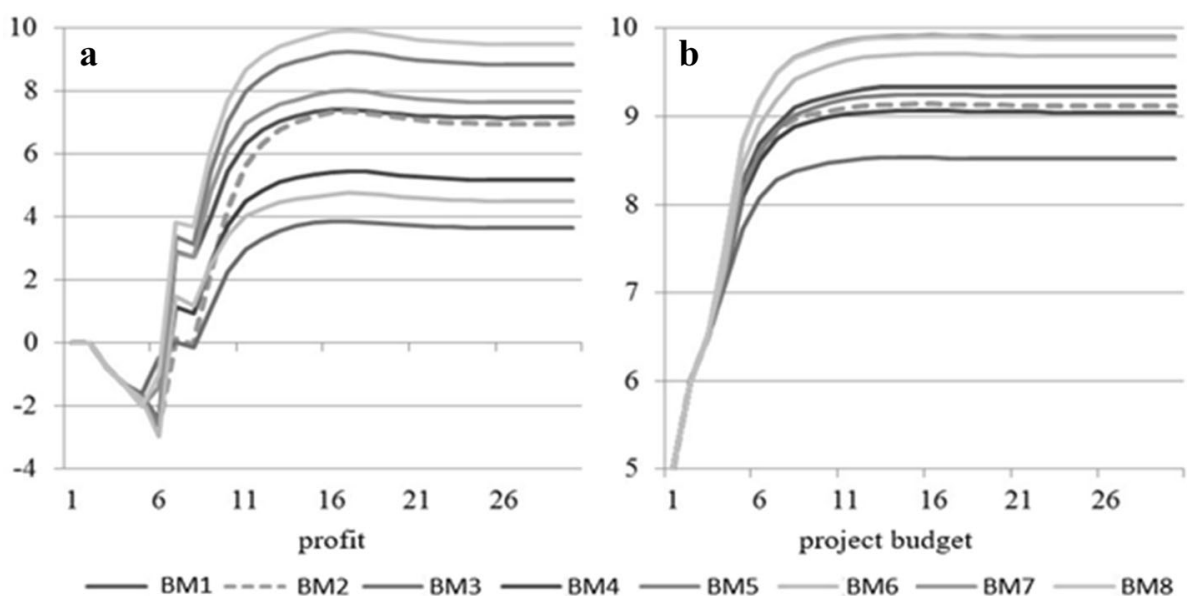

Table 3 Attractiveness rating of outsourcing business models BM1BM8. Source: Formed by the author

\begin{tabular}{lll}
\hline $\begin{array}{l}\text { Business } \\
\text { model }\end{array}$ & $\begin{array}{l}\text { Rating of attractiveness by } \\
\text { profitability }\end{array}$ & $\begin{array}{l}\text { Rating of attractiveness } \\
\text { by budget }\end{array}$ \\
\hline BM8 & 1 & 7 \\
BM5 & 2 & 4 \\
BM7 & 3 & 8 \\
BM1 & 4 & 5 \\
BM2 & 5 & 3 \\
BM4 & 6 & 2 \\
BM6 & 7 & 6 \\
BM3 & 8 & 1 \\
\hline
\end{tabular}

of faces of the simplex. If the vertice $x_{i}$ does not affect one of the vertices $Y$, or does not belong to the outsourcing business model, then the simplex is denoted as empty with the dimension $q=-1$.

Simplicial complex $K_{X}(Y, \lambda)$, constructed on the basis of the incidence matrix (4), represents the set of all simplexes $\sigma_{q}^{x}$.

The simplicial complexes constructed from the common set of vertices $V$ consist of $N$ simplexes, which differ for each outsourcing business model by dimension $q$. To calculate the connectivity of simplexes, the simplexes in the simplicial complex $K_{X}(Y, \lambda)$ are ordered by decreasing dimensionality. Based on the ordered simplexes of the simplicial complex $K_{X}(Y, \lambda)$, the first structural vector is defined $Q_{X}$ :

$Q_{X}=\left\{Q_{\max (q)}, \ldots, Q_{q}, \ldots, Q_{1}, Q_{0}\right\}$

For each dimension value $q=0,1, \ldots, \max (q)$, the number of simplexes in each equivalence class $Q_{q}$ is calculated according to the following rules:

1. If two simplexes are $q$-linked, then in complex $K_{X}(Y, \lambda)$ these simplexes are also linked for the dimension $q-1, \ldots, 1,0$. That is, if two simplexes have $q$ joint faces, then they also have $q-1, \ldots, 1$ and at least one common vertice $(q=0)$.

2. If at least one vertice of the simplex does not belong to any of the previous simplexes ordered in descending order of dimensions, the simplex is assigned to a separate equivalence class.

To estimate the degree of integration of the simplex into the structure of the whole simplicial complex, the concept of eccentricity is used. The eccentricity reflects the degree of flexibility of vertices to changes in the model and is defined by the formula:

$\varepsilon(\sigma)=\frac{\hat{q}-\tilde{q}}{\tilde{q}+1}$

where $\hat{q}$-maximum dimensionality of the simplex $\sigma, \widehat{q}=\max (q) ; \tilde{q}$-is the largest value of $q$, at which $\sigma$ becomes connected to any other simplex.

\section{Results}

The simulation of an IT enterprise functioning according to the outsourcing business models BM1-BM8 is shown in Fig. 4.

As can be seen from Fig. 4, other things being equal, the outsourcing business models differ in terms of possible levels of profitability. However, the use of a less profitable outsourcing business model may be due to lower costs (Table 3 ).

Product-based outsourcing business models are the most profitable. Thus, the most attractive in terms of profit is the outsourcing business model of developing one's own nonIT service. Characteristically, the outsourcing business model of developing one's own IT service is less profitable. The highest level of efficiency for software developers is in the BM6 and BM4 business models (Fig. 5).

In the BM5 and BM7 business models, software analysts have a greater impact on profits than software developers. 


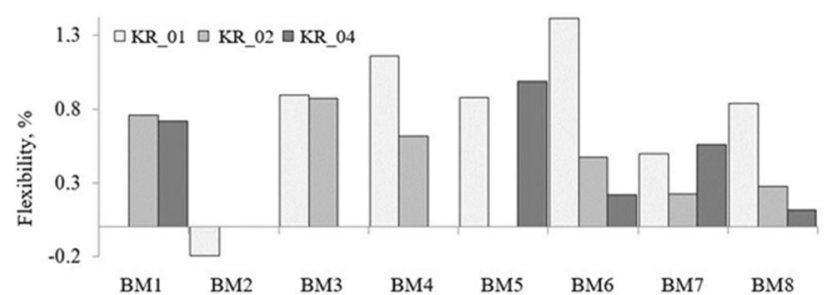

Fig. 5 Profit elasticity according to managed vertices of outsourcing business models Source: Formed by the author. Note: Key resources: KR_01-Software developers and operations personnel; KR_02marketers; KR_04—software analysts

Thus, the same factors have different effects on targets in different business models. Therefore, it is possible to find the most effective business model to achieve the target value of the strategic indicator at the expense of the manager. Atlon and Deasoft use the BM3 "Outstaffing" business model.

The simulation shows that Atlon and Deasoft can increase profits by increasing the number of projects of the same type; it is achieved by increasing spending on innovation to improve the quality of projects and reducing the duration of their development. Based on the evaluation of indicators of an enterprise development management level and BM3 "Outstaffing" business model, the simulation of changes in the strategic indicators F_01 "Profit" and F_02 "Project Budget" (Fig. 6) of Atlon and Deasoft was conducted according to the basic variant.

Using the existing BM3 "Outstaffing" business model is more profitable for Atlon. The results of modeling the hiring of an additional software developer (vertice KR_01) by enterprises are shown in Fig. 7 .

According to the calculations, hiring an additional Atlon software developer is expected to increase profits by $5.99 \%$ and budget - by $3.02 \%$. While hiring an additional Deasoft software developer will increase profits by $6.19 \%$ and budget - by $3.09 \%$. Thus, hiring an additional software developer for Deasoft is more efficient than for Atlon.

The results of modeling the expansion of sales channels using sales agent services (adding MC_03 vertice to the BM3 "Outstaffing" business model) by Atlon and Deasoft are shown in Fig. 8.
Using sales agent services by Atlon will decrease profits by $0.1 \%$ and increase budget by $0.12 \%$. While the use of sales agent services by Deasoft will decrease profit by $0.12 \%$ and increase budget by $0.13 \%$. Thus, the use of sales agent services in Atlon and Deasoft is not appropriate for the BM3 "Outstaffing" business model.

The results of modeling the change in the relationships with customers through the replacement of co-creation (removing vertice CR_01 from the business model) by special personal support (adding vertice CR_02 to the business model) in Atlon and Deasoft are shown in Fig. 9.

Replacing the co-creation of special personal support in Atlon will decrease its profit by $0.16 \%$ and increase its budget by $0.17 \%$. While in Deasoft, the profit will decrease by $0.18 \%$ and the budget will increase by $0.2 \%$.

Thus, modeling the change in the nature of customer relationships in Atlon and Deasoft shows the inexpediency of replacing co-creation with special personal support in BM3. The results of modeling the change of business model from BM3 "Outstaffing" to BM4 "Auxiliary outsourcing" in Atlon and Deasoft are shown in Fig. 10.

According to the calculations, replacing the business model would increase Atlon's profit by $14.52 \%$ while increasing the budget by $5.94 \%$. For Deasoft, the profit increase would be $16.05 \%$ with a budget increase of $6.23 \%$. The results of modeling ways to improve the business model of Atlon and Deasoft are shown in Table 4.

The results of improving the business model are shown in Table 5.

As can be seen from Table 5, the best option is the transition to the business model BM4 "Auxiliary outsourcing" (Fig. 11).

Thus, from the analysis of the available outsourcing business models of IT enterprises, similar factors and patterns in the relationship between them were identified. Using topological analysis, it is found that certain factors can be replaced without losing the integrity of the business model. However, others, primarily management costs and software vendors, cannot be removed or replaced. Using the structural connectivity analysis, it was found that the factors can be ranked as follows in terms of the level of importance for maintaining the business model: key
Fig. 6 Simulating the work of Atlon and Deasoft according to the basic variant. Source: Formed by the author

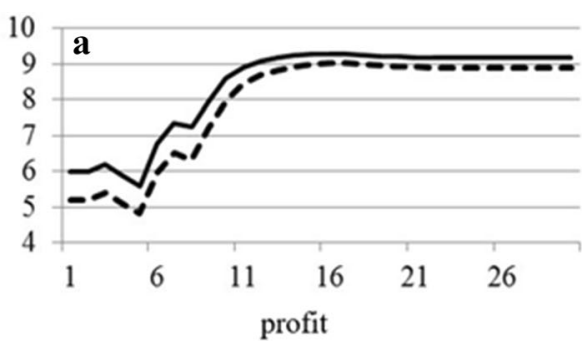

Atlon

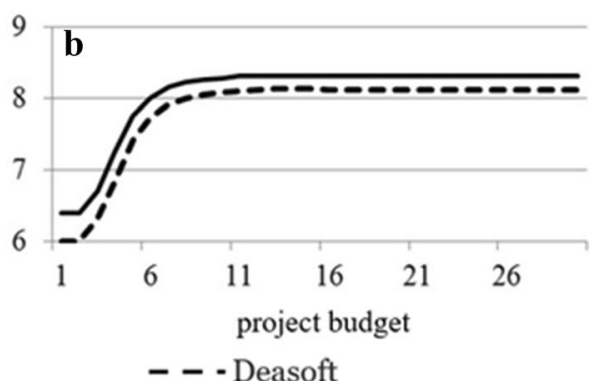


Fig. 7 Simulation of Atlon and Deasoft work under option 2hiring additional specialists without changing the outsourcing business model. Source: Formed by the author
Fig. 8 Simulation of Atlon and Deasoft work according to option 3-expansion of sales channels. Source: Formed by the author
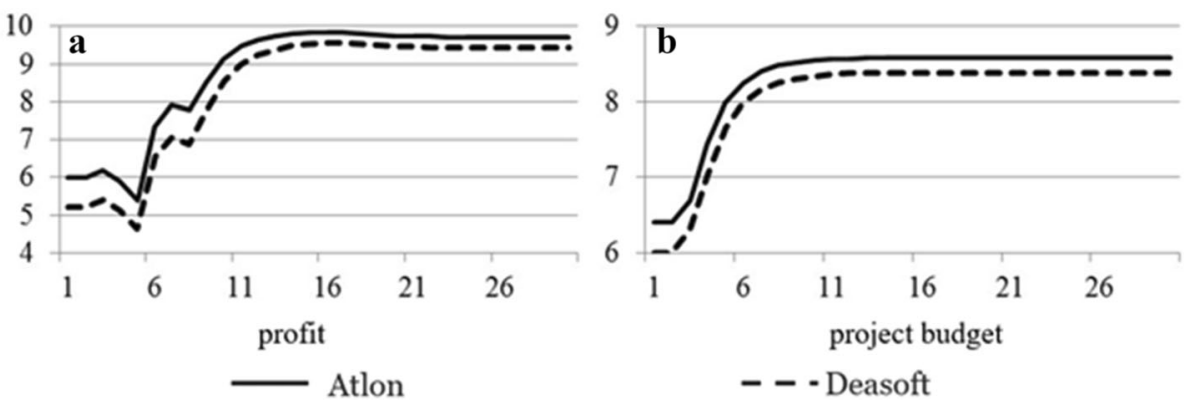

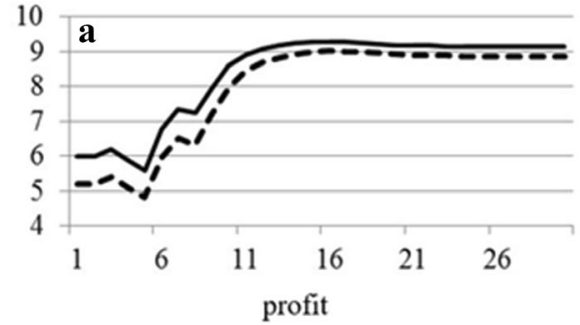

Atlon

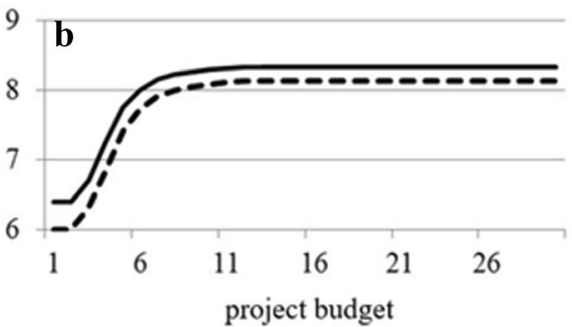

- - - Deasoft
Fig. 9 Simulation of Atlon and Deasoft work on option 4 changing the nature of customer relationships. Source: Formed by the author

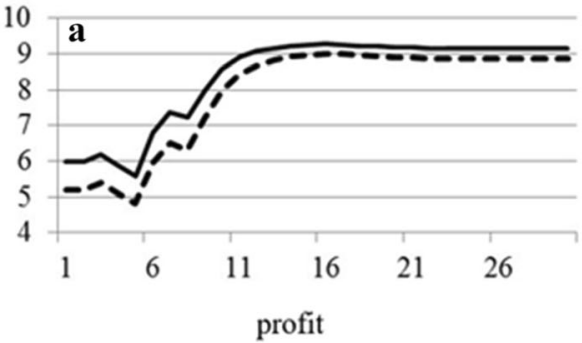

Atlon

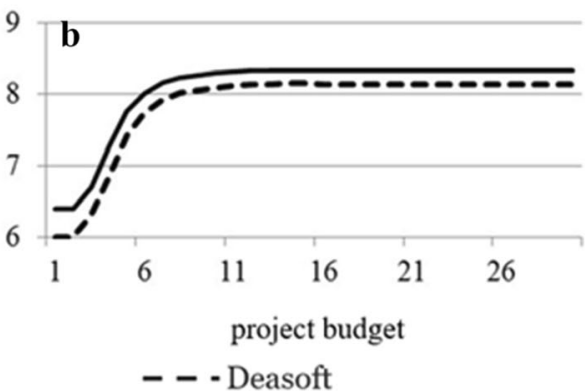

partners, key activities, customer segments, value propositions, sales channels, and relationships with customers. To make decisions to change the business model, it is proposed to use the elasticity of the target strategic indicators based on business models' managed indicators. It is substantiated that the best option for Atlon and Deasoft is the transition to an "Outsourcing" business model.

\section{Discussion}

While the balanced scorecard is used to monitor the achievement of strategic objectives, the integrated economic and organizational approach proposed in this study allows one to compare and justify ways to achieve these goals (Bhat \& Kumar, 2018). The distribution of indicators into three levels allows one to consider changes in the ways of achieving strategic indicators by changes in the outsourcing business model. At the same time, the levers of control (indicators that can be managed by a company) can remain unchanged (Gholamian et al., 2020). The presented comprehensive economic-organizational model is a system of indicators; it can be used to assess the current state and capabilities of an IT enterprise. It also allows one to look for possible areas of improvement or replacement of the outsourced business model for a more efficient operation and quick and complete achievement of the long-term goals. To do this, it is necessary to determine the necessary specific conditions for changing the outsourcing business model (Karimi-Alaghehband \& Rivard, 2020).

From the obtained results, it is obvious that the functioning of any business model is impossible without the expenses for the specialists' remuneration and management expenses. The specialists are attracted depending on the specifics of the outsourcing business model (David et al., 2017). Certain number of resource combinations may require ST_02. Only some of them are used in building an effective outsourcing business model. It is the same with the factors describing the other blocks of the outsourcing business model template: there are a certain number of 
Fig. 10 Simulation of Atlon and Deasoft work by option 5transition to BM4 "Auxiliary outsourcing" business model. Source: Formed by the author

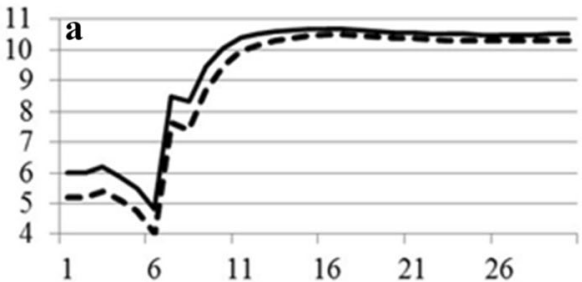

profit

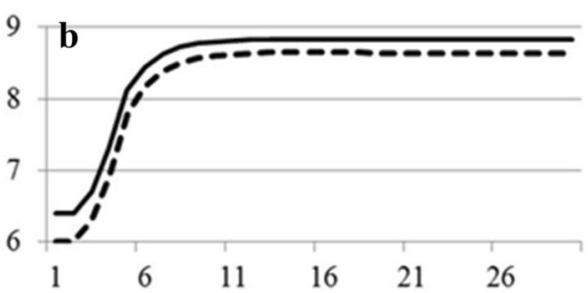

project budget

- - Deasoft

Table 4 Simulation results of Atlon and Deasoft business model improvement. Source: Formed by the author

\begin{tabular}{|c|c|c|c|c|}
\hline Option to improve the business model & $\begin{array}{l}\text { Atlon } \\
\text { Profit }\end{array}$ & $\begin{array}{l}\text { Deasoft } \\
\text { Budget }\end{array}$ & $\begin{array}{l}\text { Atlon } \\
\text { Profit }\end{array}$ & $\begin{array}{l}\text { Deasoft } \\
\text { Budget }\end{array}$ \\
\hline No change & 9.173 & 8.326 & 8.881 & 8.127 \\
\hline Hiring an additional developer & 9.712 & 8.568 & 9.426 & 8.378 \\
\hline Expansion of sales channels by using sales agent services & 9.158 & 8.329 & 8.867 & 8.136 \\
\hline Replacing co-creation with special personal support & 9.161 & 8.336 & 8.872 & 8.142 \\
\hline Transition to the BM4 "Auxiliary outsourcing" business model & 10.506 & 8.824 & 10.308 & 8.634 \\
\hline
\end{tabular}

Table 5 Comparison of ways to improve Atlon and Deasoft business model, change in $\%$ to the base variant. Source: Formed by the author

\begin{tabular}{|c|c|c|c|c|}
\hline Option to improve the business model & $\begin{array}{l}\text { Atlon } \\
\text { Profit }\end{array}$ & $\begin{array}{l}\text { Deasoft } \\
\text { Budget }\end{array}$ & $\begin{array}{l}\text { Atlon } \\
\text { Profit }\end{array}$ & $\begin{array}{l}\text { Deasoft } \\
\text { Budget }\end{array}$ \\
\hline Hiring an additional developer & +5.94 & +3.04 & +6.18 & +3.08 \\
\hline Expansion of sales channels by using sales agent services & -0.10 & +0.12 & -0.11 & +0.14 \\
\hline Replacing co-creation with special personal support & -0.16 & +0.17 & -0.18 & +0.20 \\
\hline Transition to the BM4 "Auxiliary outsourcing" & +14.52 & +5.94 & +16.05 & +6.23 \\
\hline
\end{tabular}

Fig. 11 Comparison of ways to improve the business model. Source: Formed by the author. Notes: Option 1-no change; option 2-hiring an additional software developer; option 3expanding sales channels by using sales agents; option 4replacing co-creation with special personal support; option 5-switching to BM4

"Auxiliary outsourcing" business model
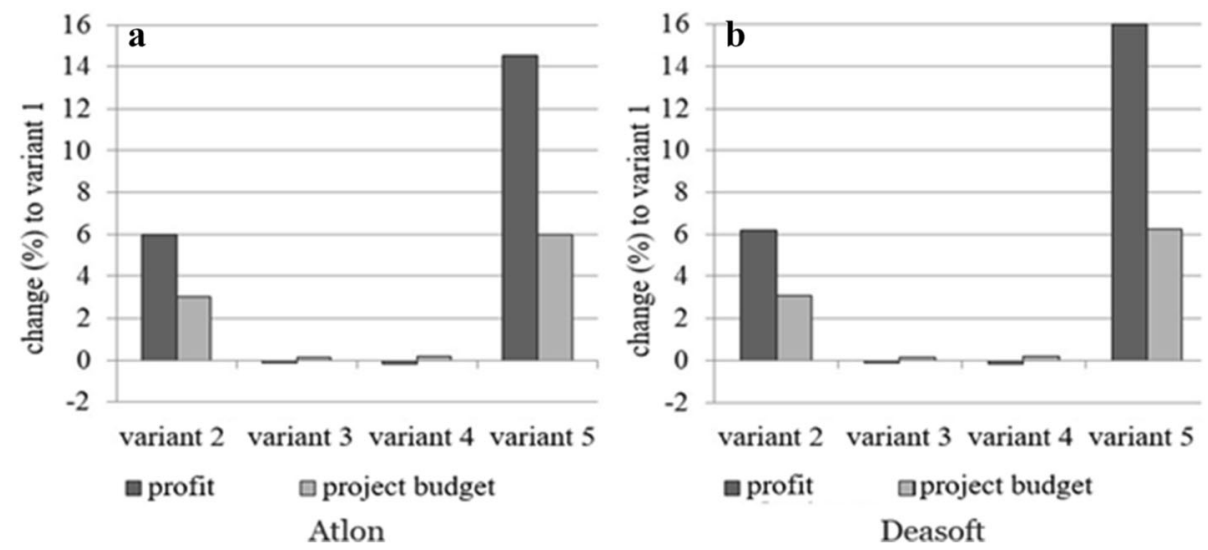

unused combinations that can form the basis of new business models (Boukadi et al., 2019).

The construction of cognitive maps of business models proposed in this study by a single set of vertices unifies their structure and shows the differences, facilitates the creation of new business models based on a combination of existing factors. Determination of the conditions of business model changes will reduce the lag between changes in 
the market situation and the adaptation of an enterprise to the new business conditions. When changing or creating a business model, it is important to ensure that its integrity is maintained (Barak \& Javanmard, 2020; Boichenko et al., 2020)

Software vendors are among the most connected factors for all business models except BM3 "Outstaffing," which involves handing over to customers their experts who will use the customer's software. For BM3 Outstaffing, the most connected are staffing agencies and professionals themselves. Removing these factors would destroy the outsourcing business model (Patel et al., 2019). BM2 business model "custom calculations" is the most related to customers who systematically use calculation results and software vendors (Iqbal et al., 2020). Consumer segment (customers who occasionally use calculation results) is less binding BM2 factor, so it can be excluded or replaced without destroying the business model. The business models BM4 "Auxiliary outsourcing" and BM6 "Software development for sale" are the most related to the core business. The least connected in the business models are sales channels, customer relationships, and, to some extent, value propositions (Buldeo Rai et al., 2019).

The study proves that the transition to other sales channels or another form of relationship with customers does not destroy the outsourcing business model. Therefore, they can be considered as the most likely options for improvement. Key activities are more connected (holistic) than value propositions and customer segments (Eggert et al., 2018). In other words, a business may refocus on other customer segments, or begin to offer different value propositions, but the outsourcing business model will remain unchanged. However, a change in the core business may lead to a change in the outsourcing business model (Trabucchi et al., 2019). A limitation of this study is that specialists may be key resources and more connected to the business model than customers, but for key activities, it all depends on the business model. In some companies, specialists may be more important; in others, specialists may be less important than key activities. In other words, sometimes it is easier to change specialists, and in other cases, it is easier to change key activities.

In the future, this study can be expanded in the context of testing the proposed approach in the enterprises of other industries. It is possible to study the impact of contractual and regulatory aspects of outsourcing business models in different countries and regions, as well as to assess the flexibility of outsourcing business models in a crisis, in the aftermath of the Covid-19 pandemic.

\section{Conclusion}

Based on the determination of the profit elasticity by manageable vertices of outsourcing business models, the most attractive by the criterion of efficiency in the form of profit is the outsourcing business model of developing an in-house non-IT service. At the same time, the outsourcing business model of developing an in-house IT service is less profitable.

Modeling the effectiveness of implementing formed outsourcing business models provides an opportunity to increase profits for the studied IT companies by increasing the number of single-type projects. This is achieved by increasing the spending on innovation to improve the quality of projects and reduce the duration of their development.

Implementing the use of sales agent services in the business model for the studied companies will reduce profits while increasing the project budget. Thus, the use of sales agent services by the investigated IT enterprises is inappropriate for the business model in the context of outstaffing. Replacing co-creation with special personal support in the studied enterprises contributes to their profit reduction when the project budget is increased.

The conducted modeling of changes in the nature of relationships with customers of the studied IT enterprises shows the inexpediency of replacing co-creation with a special personal support in the context of outstaffing business model. Based on topological analysis, it is proved that certain factors can be replaced without losing the integrity of the business model. However, there are factors affecting management costs and relationships with software vendors that cannot be removed or replaced.

The analysis of structural connectivity confirms that business model factors can be ranked as follows (in terms of the level of importance): key partners, key activities, customer segments, value propositions, sales channels, and relationships with customers. The study proves that the most effective option for improving the outsourcing business model of the studied IT companies is the transition to a pure outsourcing business model in the context of making managerial decisions on the model transformation based on the use of the elasticity level of strategic target indicators. The main premise of this is the fact that the outsourcing business model has a broader platform for the administration of enterprise functions. However, it is inappropriate to generalize all the processes that took place in it prior to outsourcing. The center of this model is the strategic intentions of the business, not the outsourced processes. The structural unit of outsourced management is important but not the main element of the management system of this model. The main one is the division of key managers, who 
form the value of a company in the market, providing a stream of income.

The scientific contribution of this study is the proposed methodological approach to assessing the effectiveness of outsourcing business models; it allows identifying model transformation components without losing its integrity. This increases the level of flexibility of the business model and its adaptability to changes in the business environment, which ensures the effectiveness of a company. Based on the application of this methodology, the strategic objectives are linked to the business model in the process of achieving them (the level of achievement of strategic objectives under the influence of the selected outsourcing business model is shown). The blocks of the outsourcing business model template are linked, which contributes to the management of the business model using a system of indicators.

This study is limited by the fact that employees may be the lead resources and are more tied to the business model than to customers. That said, for core activities, they are directly related to the business model. For some companies, employees may be more important, while for others they may be less important than core activities. This means that in some cases, the change of specialists is more effective, while in other cases the change of key activities becomes less feasible. In the long term, this study can be continued in the context of testing the proposed methodological approach to the enterprises of other sectors. In doing so, it is possible to examine the impact of contractual and regulatory aspects of outsourcing business models in different countries and regions, as well as to assess the possibilities of adapting outsourcing business models to the aftermath of COVID-19 pandemic.

Authors' Contribution FK, AS and RYe contributed equally to the experimentation. FK and RYe wrote and edited the article. AS and FK equally designed and conducted the experiment. RYe studied scientific literature about the topic. All authors read and approved the final manuscript.

Funding This research did not receive any specific grant from funding agencies in the public, commercial, or not-for-profit sectors.

Availability of Data and Material Data will be available on request.

\section{Declarations}

Conflict of interest Authors declare that they have no conflict of interests.

\section{References}

Agburu, J. I., Anza, N. C., \& Iyortsuun, A. S. (2017). Effect of outsourcing strategies on the performance of small and medium scale enterprises (SMEs). Journal of Global Entrepreneurship Research, 7(1), 26. https://doi.org/10.1186/s40497-017-0084-0

Austin-Egole, I. S., \& Iherioanma, E. B. J. (2020). Outsourcing and organizational performance: A comparative analysis of Nigeria Bottling Company Plant and Camela Vegetable Oil Company, Owerri, Imo State, Nigeria. Research on Humanities and Social Sciences, 10(12), 64-83. https://doi.org/10.7176/RHSS/10-12-09

Awa, D., \& de la Cruz, R. J. (2020). Every real symplectic matrix is a product of real symplectic involutions. Linear Algebra and Its Applications, 589, 85-95. https://doi.org/10.1016/j.laa.2019.12. 003

Balcet, G., \& Ietto-Gillies, G. (2020). Internationalisation, outsourcing and labour fragmentation: The case of FIAT. Cambridge Journal of Economics, 44(1), 105-128. https://doi.org/10. 1093/cje/bez013

Barak, S., \& Javanmard, S. (2020). Outsourcing modelling using a novel interval-valued fuzzy quantitative strategic planning matrix (QSPM) and multiple criteria decision-making (MCDMs). International Journal of Production Economics, 222, 107494. https://doi.org/10.1016/j.ijpe.2019.09.015

Bhat, S. A., \& Kumar, A. (2018). Performance evaluation of outsourcing decision using a BSC and fuzzy AHP approach: A case of the Indian coal mining organization by M., Modak, K., Pathak, KK, Ghosh [Resour. Policy 52 (2017) 181-191]: Suggested modification. Resources Policy, 55, 29-30. https:// doi.org/10.1016/j.resourpol.2017.10.005

Bhushan, U., Gujarathi, R., \& Kaur, J. (2018). Analysis of human resource outsourcing with regards to competitiveness of organizations. Open Access Journal of Science, 2(4), 265-272. https:// doi.org/10.15406/oajs.2018.02.00085

Bilan, Y., Nitsenko, V., Ushkarenko, I., Chmut, A., \& Sharapa, O. (2017). Outsourcing in international economic relations. Montenegrin Journal of Economics, 13(3), 175-185. https://doi.org/ $10.14254 / 1800-5845 / 2017.13-3.14$

Blagorazumnaia, O. (2018). Application of managerial out-technologies in the labor market. EcoSoEn, 1(4), 101-106.

Bocken, N. M., Schuit, C. S., \& Kraaijenhagen, C. (2018). Experimenting with a circular business model: Lessons from eight cases. Environmental Innovation and Societal Transitions, 28, 79-95. https://doi.org/10.1016/j.eist.2018.02.001

Boichenko, K. S., Shvydanenko, G. A., Besarab, S. A., Shvydka, O. P., \& Kyryliuk, O. V. (2020). Marketing innovations management in the context of integrated enterprise development. International Journal of Management, 11(5), 126-137. https:// doi.org/10.34218/IJM.11.5.2020.013

Boukadi, K., Grati, R., Rekik, M., \& Ben-Abdallah, H. (2019). Business process outsourcing to cloud containers: How to find the optimal deployment? Future Generation Computer Systems, 97, 397-408. https://doi.org/10.1016/j.future.2019.02.069

Buldeo Rai, H., Verlinde, S., Macharis, C., Schoutteet, P., \& Vanhaverbeke, L. (2019). Logistics outsourcing in omnichannel retail: State of practice and service recommendations. International Journal of Physical Distribution and Logistics Management, 49(3), 267-286. https://doi.org/10.1108/IJPDLM-02-20180092

Cai, W., Liu, C., Jia, S., Chan, F. T., Ma, M., \& Ma, X. (2020). An emergy-based sustainability evaluation method for outsourcing machining resources. Journal of Cleaner Production, 245, 118849. https://doi.org/10.1016/j.jclepro.2019.118849

Chen, K. S., Chang, T. C., \& Lin, Y. T. (2019). Developing an outsourcing partner selection model for process with two-sided specification using capability index and manufacturing time performance index. International Journal of Reliability, Quality and Safety Engineering, 26(03), 1950015. https://doi.org/10. 1142/S0218539319500153 
Chen, Y., Bharadwaj, A., \& Goh, K. Y. (2017). An empirical analysis of intellectual property rights sharing in software development outsourcing. MIS Quarterly, 41(1), 131-161. https://doi.org/10. 25300/MISQ/2017/41.1.07

Ciasullo, M. V., Fenza, G., Loia, V., Orciuoli, F., Troisi, O., \& Herrera-Viedma, E. (2018). Business process outsourcing enhanced by fuzzy linguistic consensus model. Applied Soft Computing, 64, 436-444. https://doi.org/10.1016/j.asoc.2017.12. 020

David, R., Banerjee, P., \& Ponnam, A. (2017). Risks perceived regarding recruitment process outsourcing: Stakeholder concerns. Journal of Global Operations and Strategic Sourcing, 10(1), 112-136. https://doi.org/10.1108/JGOSS-07-2016-0023

Drzewiecki, J. (2021). Empirical verification of relationship between organizational boundaries, business model change and outsourcing scope and maturity. European Research Studies Journal, 24(1), 1287-1311. https://doi.org/10.35808/ersj/2105

Eggert, A., Ulaga, W., Frow, P., \& Payne, A. (2018). Conceptualizing and communicating value in business markets: From value in exchange to value in use. Industrial Marketing Management, 69, 80-90. https://doi.org/10.1016/j.indmarman.2018.01.018

Evans, S., \& Bahrami, H. (2020). Super-flexibility in practice: Insights from a crisis. Global Journal of Flexible Systems Management, 21(3), 207-214. https://doi.org/10.1007/s40171020-00246-6

Gholamian, K., Vakilifard, H., Talebnia, G., \& Hejazi, R. (2020). Conceptual design of sustainable outsourcing with balanced scorecard using analytic hierarchy process: A case study for fajr jam gas refining company. International Journal of Engineering, 33(1), 112-123. https://doi.org/10.5829/ije.2020.33.01a.13

Happonen, A., \& Siljander, V. (2020). Gainsharing in logistics outsourcing: Trust leads to success in the digital era. International Journal of Collaborative Enterprise, 6(2), 150-175. https://doi.org/10.1504/IJCENT.2020.110221

Iqbal, J., Ahmad, R. B., Khan, M., Alyahya, S., Nizam Nasir, M. H., Akhunzada, A., \& Shoaib, M. (2020). Requirements engineering issues causing software development outsourcing failure. PLoS ONE, 15(4), e0229785. https://doi.org/10.1371/journal.pone. 0229785

Johansson, B., Lilja, M., \& Tarland, L. (2021). The need for boundary spanners in an offshore insourcing strategy. Procedia Computer Science, 181, 572-579. https://doi.org/10.1016/j.procs.2021.01. 204

Jokipii, A., \& Di Meo, F. (2019). Internal audit function characteristics and external auditors' co-sourcing in different institutional contexts. International Journal of Auditing, 23(2), 292-307. https://doi.org/10.1111/ijau.12162

Karimi-Alaghehband, F., \& Rivard, S. (2020). IT outsourcing success: A dynamic capability-based model. The Journal of Strategic Information Systems, 29(1), 101599. https://doi.org/10. 1016/j.jsis.2020.101599

Klafke, R., Picinin, C. T., \& Chevarria, D. G. (2021). Considerations regarding donation and value co-creation in times of COVID-19 pandemic. Global Journal of Flexible Systems Management, 22(4), 357-376.

Könning, M., Westner, M., \& Strahringer, S. (2019). A systematic review of recent developments in IT outsourcing research. Information Systems Management, 36(1), 78-96. https://doi.org/ $10.1080 / 10580530.2018 .1553650$

Liu, Z., Jayaraman, V., \& Luo, Y. (2017). The unbalanced indirect effects of task characteristics on performance in professional service outsourcing. International Journal of Production Economics, 193, 281-293. https://doi.org/10.1016/j.ijpe.2017.06.003

Mason, K., \& Mouzas, S. (2012). Flexible business models. European Journal of Marketing, 46(10), 1340-1367. https://doi.org/10. 1108/03090561211248062
Masudin, I., Ramadhani, A., Restuputri, D. P., \& Amallynda, I. (2021). The effect of traceability system and managerial initiative on Indonesian food cold chain performance: a Covid19 pandemic perspective. Global Journal of Flexible Systems Management, 22(4), 331-356.

Mayer, F. W., \& Phillips, N. (2017). Outsourcing governance: States and the politics of a 'global value chain world.' New Political Economy, 22(2), 134-152. https://doi.org/10.1080/13563467. 2016.1273341

Modak, M., Ghosh, K. K., \& Pathak, K. (2019). A BSC-ANP approach to organizational outsourcing decision support-A case study. Journal of Business Research, 103, 432-447. https://doi. org/10.1016/j.jbusres.2018.01.040

Modak, M., Pathak, K., \& Ghosh, K. K. (2017). Performance evaluation of outsourcing decision using a BSC and Fuzzy AHP approach: A case of the Indian coal mining organization. Resources Policy, 52, 181-191. https://doi.org/10.1016/j.resour pol.2017.03.002

Moradi, M., Moradi, M., Bayat, F., \& Toosi, A. N. (2019). Collective hybrid intelligence: Towards a conceptual framework. International Journal of Crowd Science, 3(2), 198-220. https://doi.org/ 10.1108/IJCS-03-2019-0012

Munjal, S., Requejo, I., \& Kundu, S. K. (2019). Offshore outsourcing and firm performance: Moderating effects of size, growth and slack resources. Journal of Business Research, 103, 484-494. https://doi.org/10.1016/j.jbusres.2018.01.014

Mussapirov, K., Jalkibaeyev, J., Kurenkeyeva, G., Kadirbergenova, A., Petrova, M., \& Zhakypbek, L. (2019). Business scaling through outsourcing and networking: Selected case studies. Entrepreneurship and Sustainability Issues, 7(2), 1480. https:// doi.org/10.9770/jesi.2019.7.2(48)

Nagurney, A., Yu, M., \& Besik, D. (2017). Supply chain network capacity competition with outsourcing: A variational equilibrium framework. Journal of Global Optimization, 69(1), 231-254. https://doi.org/10.1007/s10898-017-0497-x

Osterwalder, A., \& Euchner, J. (2019). Business model innovation: An interview with Alex Osterwalder. Research-Technology Management, 62(4), 12-18. https://doi.org/10.1080/08956308. 2019.1613114

Pankowska, M. (2019). Information technology outsourcing chain: Literature review and implications for development of distributed coordination. Sustainability, 11(5), 1460. https://doi.org/ 10.3390/su11051460

Parameswar, N., \& Dhir, S. (2020). Interpretive ranking of choice of interaction of parent firms post-international joint venture termination using TISM-IRP. Global Journal of Flexible Systems Management, 21(1), 1-16. https://doi.org/10.1007/s40171-01900227-4

Patel, C., Budhwar, P., Witzemann, A., \& Katou, A. (2019). HR outsourcing: The impact on HR's strategic role and remaining in-house HR function. Journal of Business Research, 103, 397-406. https://doi.org/10.1016/j.jbusres.2017.11.007

Paul, S. K., \& Chowdhury, P. (2020). Strategies for managing the impacts of disruptions during COVID-19: an example of toilet paper. Global Journal of Flexible Systems Management, 21(3), 283-293.

Rehman, S., Tiwari, A., Turner, C., \& Williams, L. (2018). A framework for innovation outsourcing. International Journal of Business Innovation and Research, 16(1), 79-111. https://doi. org/10.1504/IJBIR.2018.091085

Richter, N., Jackson, P., \& Schildhauer, T. (2018). Outsourcing creativity: An abductive study of open innovation using corporate accelerators. Creativity and Innovation Management, 27(1), 69-78. https://doi.org/10.1111/caim.12252

Singh, R., \& Gonsalves, T. A. (2019). Making the value of data determine the security: A case study of rural business process 
outsourcing. Journal of Information Security and Applications, 44, 104-116. https://doi.org/10.1016/j.jisa.2018.11.005

Tan, G. N. D. (2021). A business-model approach on strategic flexibility of firms in a shifting value chain: The case of coffee processors in amadeo and silang, Cavite, Philippines. Global Journal of Flexible Systems Management, 22(1), 17-28. https:// doi.org/10.1007/s40171-020-00255-5

Trabucchi, D., Talenti, L., \& Buganza, T. (2019). How do big bang disruptors look like? A business model perspective. Technological Forecasting and Social Change, 141, 330-340. https://doi. org/10.1016/j.techfore.2019.01.009

Trang, M. N. (2017). Compulsory corporate cyber-liability insurance: Outsourcing data privacy regulation to prevent and mitigate data breaches. Minnesota Journal of Law, Science and Technology, $18,389-425$.

Vergara, I. G. P., Gómez, M. C. L., Martínez, I. L., \& Hernández, J. V. (2021). Strategies for the preservation of service levels in the inventory management during COVID-19: A case study in a company of biosafety products. Global Journal of Flexible Systems Management, 22, 65-80. https://doi.org/10.1007/ s40171-021-00271-Z

Vitasek, K., \& Manrodt, K. (2012). Vested outsourcing: A flexible framework for collaborative outsourcing. International Journal, 5(1), 4-14. https://doi.org/10.1108/17538291211221924

Wallo, A., \& Kock, H. (2018). HR outsourcing in small and mediumsized enterprises. Personnel Review, 47(5), 1003-1018. https:// doi.org/10.1108/PR-03-2017-0066

Yuan, Y., Chu, Z., Lai, F., \& Wu, H. (2020). The impact of transaction attributes on logistics outsourcing success: A moderated mediation model. International Journal of Production Economics, 219, 54-65. https://doi.org/10.1016/j.ijpe.2019.04. 038

Zhu, W., Ng, S. C., Wang, Z., \& Zhao, X. (2017). The role of outsourcing management process in improving the effectiveness of logistics outsourcing. International Journal of Production Economics, 188, 29-40. https://doi.org/10.1016/j.ijpe.2017.03. 004

\section{Key Questions}

1. What business model is the most attractive in terms of efficiency criterion in the form of profit?

2. How to increase profits for the studied IT companies?

3. How to improve the outsourcing business model of the studied IT companies?
Publisher's Note Springer Nature remains neutral with regard to jurisdictional claims in published maps and institutional affiliations.

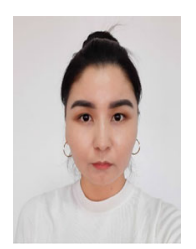

Flora Kulembayeva is a $\mathrm{PhD}$ Student of the Educational Program "Economics", Narxoz University, Almaty, Kazakhstan. Research interests: business models, economic efficiency, non-IT services, IT services, IT companies, customer groups, marketplace, business activities, investment, competitive position, global market, economic system, and entrepreneurship.

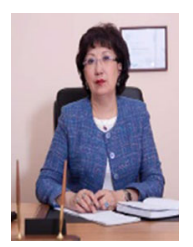

Aruzhan Seitkaziyeva is a Doctor of Economic Sciences, Professor of the SED Social Sciences, Narxoz University, Almaty, Kazakhstan. Research interests: economic efficiency, modern enterprise, customer relations, customer groups, outsourcing, outsourcing solutions, business activities, investment, competitive position, entrepreneurship global market, economic system, labor, and third-

party resources.

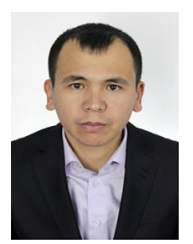

Rakymzhan Yelshibayev is a $\mathrm{PhD}$ of Economic Sciences, Professor of the Educational Program "Economics", Narxoz University, Almaty, Kazakhstan. Research interests: business models, economic efficiency, project budget, financial resources, markets, customer groups, business activities, investment, competitive position, global market, entrepreneurship, economic system, and 